\title{
Effect of Chemicals Treatments on the Morphological, Mechanical, Thermal and Water Uptake Properties of Polyvinyl Chloride/ Palm Fibers Composites
}

\author{
Hamida Boussehel ${ }^{1 *}$, DjamelEddine Mazouzi ${ }^{2}$, Noureddine Belghar $^{3}$, Belhi Guerira ${ }^{1}$, Mohamed Lachi $^{4}$ \\ ${ }^{1}$ Laboratory of Mechanical Engineering LGM, University of Biskra, Algeria \\ ${ }^{2}$ Laboratory of Molecular Chemistry and Environment LCME, University of Biskra, Algeria \\ ${ }^{3}$ Laboratory of Materials Engineering and Energy LGEM, University of Biskra, Algeria \\ ${ }^{4}$ Laboratory GRESPI / THERMAL, University of Reims Champagne Ardenne, UFR Sciences Exactes et Naturelles, Moulin de \\ la Housse, 51687 Reims cedex 2, France
}

Corresponding Author Email: h.boussehel@univ-biskra.dz

https://doi.org/10.18280/rcma.290101

Received: 9 September 2018

Accepted: 11 December 2018

\section{Keywords:}

poly (vinyl chloride), palm fibers, acetylation, alkali, mechanical, thermal, water absorption

\begin{abstract}
The use of natural resources in composite materials becomes more frequently, as they are low-cost and lightweight materials. In addition, industrial trends tend towards Eco-products, hence the importance of integrating natural products that are recyclable and easily degradable. Aim of this study is prepared polymer composites of polyvinyl chloride (PVC) using palm fibers at different loading (10 and $30 \%$ by weight). Improving the interfacial adhesion between matrix- filler interfaces using chemical modification of date palm fibers (DPF) by two types of treatments (acetylation, alkali). The effect of chemical treatment and fiber content on morphological, thermal, mechanical and water absorption properties of composites have been studies. It was found that the use of treated fibers in PVC composites improves the mechanical properties and decomposition temperature, and reduce water absorption of the composites.
\end{abstract}

\section{INTRODUCTION}

Composite materials are widely used all over the world in the manufacture of building materials, automobiles, naval parts and others. Composite materials consist of two constituents namely a matrix and reinforcement [1]. Synthetic materials have good mechanical properties and durability, but due to the environmental awareness, these materials have some criticisms because they are not easily biodegradable [2]. For Thus, efforts are being made to invent environmentally friendly composite materials to replace synthetic reinforcements such as glass, carbon, aramid fibers, etc., using natural cellulosic fibers like jute [3], coconut [4], sisal [5-7], bamboo [8-9], kenaf [10], sugar cane and rice [11-12]. The date palm (Phoenix dactylifera L) other source of cellulosic fibers with attractive morphology properties, has a fibrous structure can be extracted from different parts of plant such as: leaf fibers in the peduncle, bast fibers in the stem, wood fibers in the trunk and surface fibers around the trunk [13]. In Algeria, date palm is particularly abundant in Saharan oasis (more than 18.6 million date palms). The residual waste from these plants are incinerated or thrown every year after the harvest, generating more than 200,000 tonnes of waste causing major inconvenience in nature [14].

The effectiveness of composite materials depends to their ability to transfer stresses from the continuous phase (polymer matrix) to the dispersed phase (fillers). They are obtained when there is a good adhesion between surface of polymer and fibers with well dispersed in the matrix [15]. It is well known that the natural fillers are hydrophilic materials creates difficulties in achieving adhesion with polymer chains; generates voids around the fibers in composites, resulting in higher water uptake [16]. For thus, the treatment of natural fillers and some additives were used in the composite to improves charge-matrix compatibility, such as such as alkali treatment or mercerization, silanization, acetylation, benzoylation, acrylation, maleated coupling agents, isocyanates, permanganate treatment and plasma treatment [17-20].

Sodium hydroxide (Alkali treatment) is commonly used in Modification of the fiber, which decrease hydrogen bindings in cellulose and remove hydroxyl groups that tend to bind to water molecules to reducing the ability of fibers to absorb moisture [21]. In addition, acetylation is one of the most studied reactions for lignocellulosic materials. The principle of the method consists in reacting the hydroxyl groups $(-\mathrm{OH})$ of the fibers components, i.e. lignin, hemicelluloses, and those of amorphous cellulose with acetyl groups $\left(\mathrm{CH}_{3} \mathrm{CO}^{-}\right)$[22]. A reduction of about $50 \%$ in moisture absorption for acetylated jute fibers and up to $65 \%$ for acetylated pine fibers with increasing in shear strength of acetylated fiber composites has been reported in the literature [23-25].

Polyvinyl chloride (PVC) is among of many polymers that have been used as matrix in composites material, it is a thermoplastic material widely used in the fields of automotive, housing and construction, due to their high mechanical strength, and corrosion resistance. In addition, it is easy to manufacture and suitable for engineering applications for its hardness and flexibility [26]. However, PVC is not biodegradable; it is a contaminant material due to the release of harmful substances into the atmosphere, such as hydrogen chloride and dioxins, during processing or decomposition [2728]. The combination of PVC and natural fibers is an interesting because of the ecological friendliness of natural 
fibers.

The aim of this paper is to compare the impact of chemical treatment on the mechanical, water uptake and thermal properties of a palm date fiber-reinforced polyvinyl chloride (PVC) composites. The chemical treatments used in this work, alkali $\mathrm{NaOH}$, and acetylation, have been chosen because they exhibit a different interaction mechanism with both fibers and polymer matrix. The properties of composites prepared with chemically-treated fibers will be compared to results obtained from untreated fibers composite as well as neat polymer.

\section{MATERIAL AND METHODS}

\subsection{Materials}

The polymer used as matrix was polyvinyl chloride (PVC) also containing plasticizer, stabilizer, and lubricant provided by the national unity of cable industry, located in Biskra southeastern Algeria. The physical characteristics of the polymer are listed in Table 1 .

Table 1. Properties of polyvinyl chloride (PVC)

\begin{tabular}{cc}
\hline Polymerization degree & 1250-1450 \\
\hline Density $\left(\mathrm{g} / \mathrm{cm}^{3}\right)$ & $0.43-0.50$ \\
Melt flow index at $200^{\circ} \mathrm{C}(\mathrm{g} / \mathrm{s})$ & $\geq 10$ \\
Moisture content $(\%)$ & $\leq 0.3$ \\
Sulphate ash $(\%)$ & $\leq 0.1 \%$ \\
\hline
\end{tabular}

The leaves of the date palm were collected from local agricultural resources (Biskra region, Algeria). They were washed several times with water to remove impurities and dried in the open air for 24 hours. After this, they are ground and sieved and stored in polyethylene bags for further compounding. Sodium hydroxide, ethanol, acetic acid, acetic anhydride, sulphuric acid and hydrochloric acid, were collected from reactive grade from Sigma-Aldrich, were used for the fiber surface treatments.

\subsection{Chemical treatments of palm fibers}

Palm fibers were subjected to the following surface treatments, in order to improve their interfacial adhesion with PVC matrix.

\subsubsection{Alkali treatment}

Palm fibers were treated with an aqueous solution of $\mathrm{NaOH}$ $(5 \mathrm{wt} \%)$. The fibers were immersed in the solution during $2 \mathrm{~h}$ at $50{ }^{\circ} \mathrm{C}$ temperature and then washed several times with distilled water containing acetic acid in order to neutralize the excess sodium hydroxide. After they are washed with distilled water until $\mathrm{pH}$ value of 7 was attained. The palm fibers were dried at $80{ }^{\circ} \mathrm{C}$ for $24 \mathrm{~h}$ in a vacuum oven.

\subsubsection{Acetylation treatment}

Palm fibers are immersed in acetic acid solution at $25^{\circ} \mathrm{C}$ for $45 \mathrm{~min}$, and then they are decanted and immersed in a solution of acetic anhydride with a few drops of sulfuric acid for 2 hours at $50{ }^{\circ} \mathrm{C}$. The fibers are filtered and washed with distilled water to remove excess acetic acid, followed by drying in an oven at $80^{\circ} \mathrm{C}$ for 24 hours.

\subsection{Preparation of PVC composites}

PVC powder and the various additives were placed in a mixer at a speed of $3000 \mathrm{rpm}$ at $70{ }^{\circ} \mathrm{C}$ below the glass transition temperature of pure PVC powder. The different formulations obtained were used to prepare films by the calendering process at $160{ }^{\circ} \mathrm{C}$ in a "SCHWABENTHAN polymix 200 p" calender. After the addition of the matrix the palm fiber was added as soon as the polymer had reached a steady plastifying state. Before mixing, the fibers were dried in a vacuum oven at $75{ }^{\circ} \mathrm{C}$ for $24 \mathrm{~h}$ to prevent the formation of porous products by water evaporation during the composite preparation. The fiber content in the composites was 0,10 and $30 \mathrm{wt} \%$. The molten mix was transferred to a preheated press at $160{ }^{\circ} \mathrm{C}$ under a pressure of 300 bar in a hydrolical press "SWHWABENTHAN polystat 300s" for 5 min molder for specimen fabrication.

\subsection{Characterization}

\subsubsection{FTIR analysis}

Fourier transform infrared spectroscopy (FTIR) spectra were recorded on SHIMADZU 8400S spectrometer to analysis the possible chemical bonding existing in the untreated and treated palm fibers using $\mathrm{KBr}$ pellets containing $1 \%$ of fibers finely ground at a range of $4000-400 \mathrm{~cm}^{-1}$.

\subsubsection{Morphological analysis}

The morphology of the virgin PVC and the composites were studied using a Quanta FEG250scanning electron microscope (SEM) operating at $15 \mathrm{kV}$. The specimens were carried out under liquid nitrogen. They were coated with a 50-100 $\mu \mathrm{m}$ layer of gold to avoid sample charging under the electron beam.

\subsubsection{Tensile tests}

The different composite samples PVC/treated and untreated palm fibers were subjected to tensile tests according to ASTM D638, using Zwick / Roell Z50 testing machine at $1 \mathrm{~mm} / \mathrm{min}$ crosshead speed preventing the viscoelastic effect. Five measurements were conducted for each sample, and the results were averaged to obtain a mean value.

\subsubsection{Hardness test}

Shore hardness A of the samples was evaluated by using a hardness tester type Zwick/Roell. Samples were placed on a horizontal surface. Tester was kept in vertical position and pressed on the specimen so that the presser foot was parallel to specimen. Five readings at different points were noted, and average value is reported according to ISO 7619-1:2010.

\subsubsection{Thermal analysis}

Thermogravimetric analysis (TGA) was performed to determine weight loss as a function of temperature using SDT Q600 instrument. A sample of initial mass of 5-30 mg was introduced into a platinum crucible, the sample mass (TGA) variation was then measured as a function of temperature (or time) under an inert nitrogen atmosphere from $20^{\circ} \mathrm{C}$ to $700{ }^{\circ} \mathrm{C}$, at a heating rate of $10^{\circ} \mathrm{C} / \mathrm{min}$.

\subsubsection{Water absorption}

Water absorption of PVC/palm fiber composites was carried out according to ASTM D570-98 standard test method. The PVC/palm fiber composites were cut into rectangular shape $\left(20 \times 20 \times 2 \mathrm{~mm}^{3}\right)$ and then immersed in a distill water 
bath and then the specimens were removed periodically from water, and the increase in their weight was measured on a balance with a precision of $0.0001 \mathrm{~g}$ over a period of $600 \mathrm{~h}$. The percentage gain at any time $\left(W_{t}\right)$ was calculated according to $\mathrm{Eq}(1)$;

$$
W_{t}(\%)=\frac{W_{w}-W_{0}}{W_{0}} \times 100
$$

where, $W_{0}$ and $W_{w}$ denote the initial weight of material and weight of material after exposure to water absorption, respectively.

\section{RESULTS AND DISCUSSION}

\subsection{FTIR results}

Figure 1 shows the IR spectra of untreated and treated date palm fibers. Untreated fibers (Figure 1.a) shows characteristics peaks; the broad peak at $3418 \mathrm{~cm}^{-1}$ which is related to the stretching of $\mathrm{OH}$ groups in celluloses and lignins [29]. The peaks at $2919 \mathrm{~cm}^{-1}, 2849 \mathrm{~cm}^{-1}$ respectively attributed to symmetric and asymmetric elongation vibrations of the $\mathrm{CH}$ bonds of the $-\mathrm{CH}_{2}$ group of the cellulose and lignin segments [30]. However, the strong and sharp peak at $1732 \mathrm{~cm}^{-1}$ attributed to $>\mathrm{C}=\mathrm{O}$ stretching vibration of hemicellulose [31]. The bands at 1622 and $1651 \mathrm{~cm}^{-1}$ are due to the water absorbed by the untreated palm fiber because of its pronounced hydrophilic character [32]. A small peak at $1513 \mathrm{~cm}^{-1}$ corresponds to the vibration of the benzene ring of lignin [33]. The peaks at 1460, 1435 and $1383 \mathrm{~cm}^{-1}$ are due to the deformation vibrations of the $-\mathrm{CH}_{2}$ groups and $\mathrm{CH}_{3}$, contained in lignin structures and hemicellulose. Peak at $1229 \mathrm{~cm}^{-1}$ exhibits the elongation vibration of the $\mathrm{C}-\mathrm{O}$ bond of lignin. The small peak found at $1159 \mathrm{~cm}^{-1}$ corresponds to the vibration of $\mathrm{C}-\mathrm{O}-\mathrm{C}$ responsible for $\beta$-glucosidic bonds in cellulose and hemicellulose [34]. The elongation band of the $\mathrm{C}-\mathrm{H}$ bond of lignin appears clearly by the peak $1107 \mathrm{~cm}^{-1}$.

In acetylated fibers spectrum (Figure 1.b) there is a reduction on the intensities of the bands assigned to the substitution of the hydroxyl groups by the acetyl groups mainly those at $3418 \mathrm{~cm}^{-1}$ [35]. The absorbance in the region 1737 and $1229 \mathrm{~cm}^{-1}$ is due to the esterification of the hydroxyl groups resulting in increased stretching vibration of the carbonyl group $(\mathrm{C}=\mathrm{O})$. The spectrum of unmodified fiber shows an absorption peak at $1383 \mathrm{~cm}^{-1}$ attributed to the $-\mathrm{C}-\mathrm{H}$ bending vibration. After esterification, the added contribution of the acetyl $\left(-\mathrm{C}-\mathrm{CH}_{3}\right)$ stretching vibration intensifies this absorption peak [36-37].

The acetylation reaction of cellulosic fibers with acetic anhydride has been confirmed by the FTIR analysis, this reaction is carried out as follows:

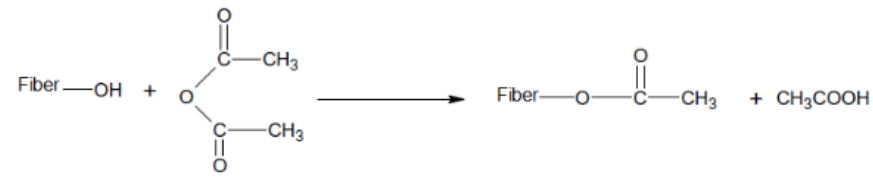

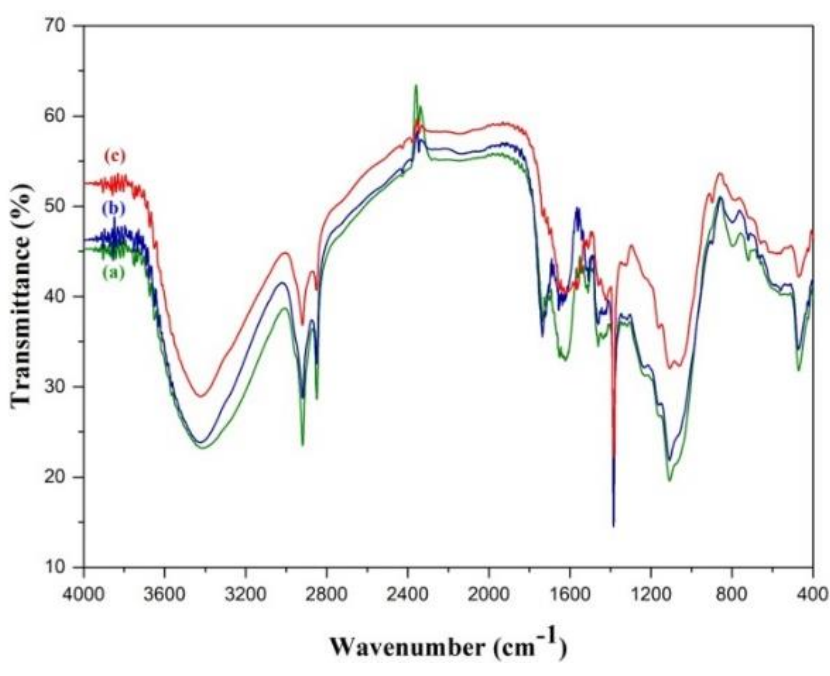

Figure 1. FTIR spectra of (a) untreated (b) acetylated and (c) alkali treated palm fibers

Alkali fibers spectrum (Figure 1. c), have the lowest amplitude, confirming that the chemical treatment reduces the effect and number of $\mathrm{OH}$ links. The intensity of the peaks located at 2920 and $2851 \mathrm{~cm}^{-1}$ decreased sharply, these two peaks correspond to the vibration of the $\mathrm{C}-\mathrm{H}, \mathrm{C}-\mathrm{H}_{2}$ and $\mathrm{C}-\mathrm{H}_{3}$ linkages of the lignins [38]. The alkaline treatment induces the partial disappearance of hemicellulose and lignin, confirmed by the disappearance of the band which characterizes the carbonyl group observed at $1735 \mathrm{~cm}^{-1}$. a decrease in the peak intensity at $1421 \mathrm{~cm}^{-1}$ corresponding to the deformation of the $-\mathrm{CH}_{2}$ group of lignin with the disappearance of the peak at $1460 \mathrm{~cm}^{-1}$ due to the aromatic rings of lignin is observed. It can also be seen that the intensity of the peak attributed to the vibration of the benzene ring of lignin between 1577 and 1507 $\mathrm{cm}^{-1}$ has decreased $[39,40]$. The reaction is carried out as follows.

Fiber $-\mathrm{OH}+\mathrm{NaOH} \longrightarrow$ Fiber $-\mathrm{O}^{-} \mathrm{Na}^{+}+\mathrm{H}_{2} \mathrm{O}$

\subsection{Characterization of PVC composites}

\subsubsection{Scanning electron microscopy}

The effect of chemical treatments of the palm fibers surface on the interfacial adhesion of PVC / palm fiber composites was studied by examining the fracture surfaces of composites with SEM. The SEM micrographs of the fracture surface of untreated and treated composites containing $30 \mathrm{phr}$ of fibers can be seen in Figure 2a, b, c, and d. Examination of the fracture surface of the virgin polyvinyl chloride matrix (Figure 2.a) shows a very smooth and very homogeneous surface. Moreover, for untreated composites PVC/UPF (Figure 2.b) indicates that there are voids between the fibers and the matrix, which proves the incompatibility of the two phases because of the poor interfacial adhesion and the difference in the energies of the free surface of the hydrophilic palm fiber and the hydrophobic polymer. This facilitates the loosening of the fiber during the fracture [41].

The use of treated fibers with polymer chains (Figure 2.c, d), reduce the detachment and absence of aggregates of fibers. The empty spaces are smaller, or have disappeared most of the time. The use of the alkaline treatment also removes waxes from the surface of the fibers and promotes good chemical bonding between the fibers and the matrix especially when the 
acetylation treatment is used. This improvement leads to the good wettability between the fiber and the polymer matrix, which results in a better dispersion of the fibers and in the reduction of the energy and the polarity of the charge. All these observations are consistent with the results of the mechanical tests [22, 42-44].
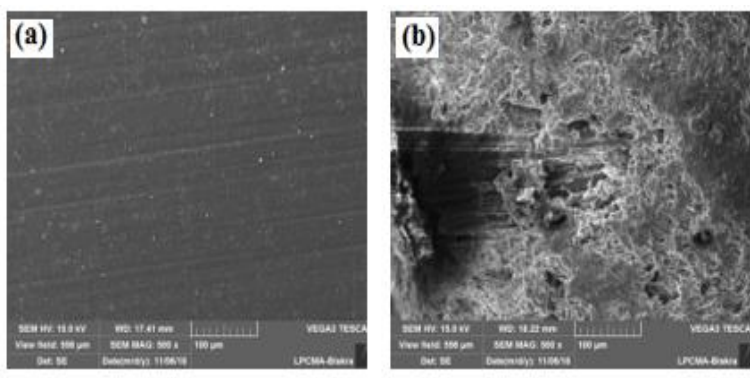

P
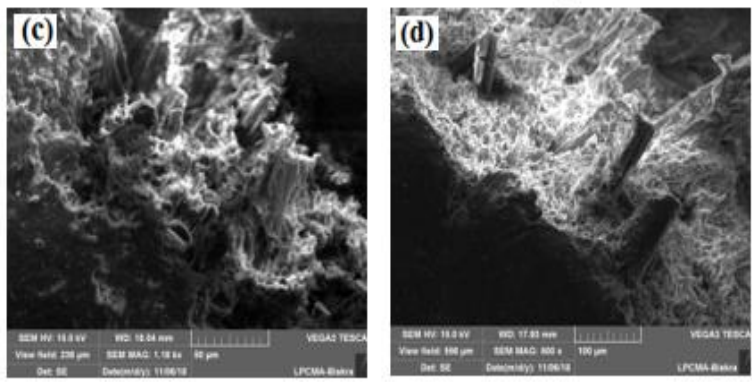

Figure 2. SEM micrographs of PVC composites with; (a) neat PVC, (b) untreated fibers, (c) acetylated and (d) alkali treated palm fibers

\subsubsection{Mechanical characterization}

The mechanical properties of thermoplastic matrix composites such as PVC depend on several factors, such as the dispersion of fibers, the amount of air stored in the composite during mixing [45]. However, according to Georgopoulos et al [46], it should be noted that the fiber-matrix interface plays an essential role in ensuring that each element constituting the composite contributes to the final property of the material.

The tensile strength of PVC composites reinforced with untreated palm fibers decreased with increasing of loading ratio compared to the neat PVC (Figure 3). These results are in agreement with those found by Yao et al [47], they recorded a decrease in the tensile strength of the composites with the increase of the loading rate, thus increases the interfacial air and weakens the interactions between the charge and the matrix. For the composites reinforced with alkalited and acetylated fibers we noted improvement in tensile strength of composites compared to untreated composites. This increase due to the better dispersion of the filler and in particular to the reinforcement of the interfacial bonds between the PVC and the treated palm fibers $[25,48]$. The maximum tensile strength is $8.42 \mathrm{MPa}$ achieved for the composites reinforced by acetylated fibers at $10 \mathrm{wt} \%$ of the fiber rate.

The evolution of the elongation at break of the treated and untreated composites as a function of the palm fiber content (Figure 4) characterized by a significant decrease in elongation at break for composites reinforced with untreated fiber (PVC/UPF), this decrease due to the hydrophilic nature of the untreated fibers that absorb more moisture and cause swelling in composites which causes the embrittlement of the material. On the other hand to the increasing volume occupied by the fibers, leads to defects in the material and reduces interchain interactions [49].

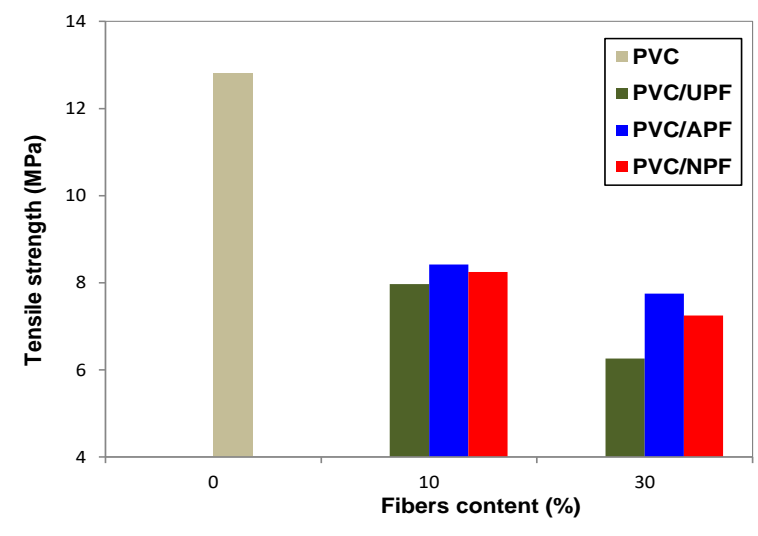

Figure 3. Tensile strength of neat PVC and composites with treated and untreated fibers

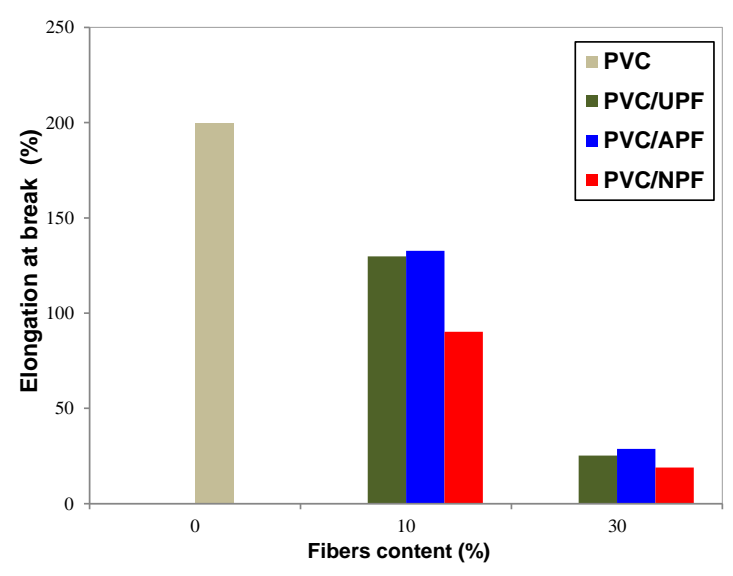

Figure 4. Elongation at break of neat PVC and composites with treated and untreated fibers

The addition of acetylated palm fibers, allows a certain increase in elongation at break compared to the composites made with the untreated fibers, estimated at 131.7 and $28.8 \%$ for the formulations at 10 and $30 \mathrm{wt} \%$ respectively. This improvement is attributed to the good dispersion of fibers which lends some flexibility to the material. Moreover, it is noted that the addition of the alkalited fibers in PVC matrix (PVC/NTF) does not bring any improvement in the deformation; such a result is confirmed by Nedjma et al. [50].

\subsubsection{Shore hardness}

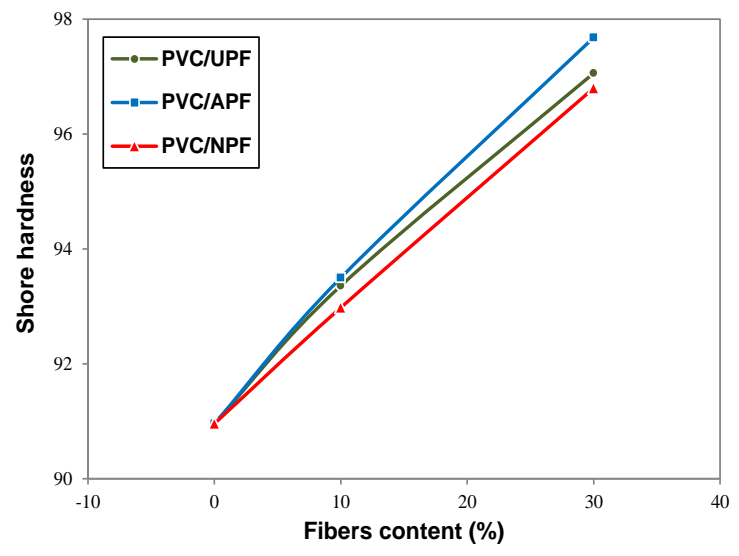

Figure 5. Shore hardness of neat PVC and composites with treated and untreated fibers 
Shore hardness of PVC composites with untreated palm fibers (Figure 5), increase with the increasing of fibers. These results indicate the decrease in flexibility and the increase in stiffness [51]. For acetylated composites (PVC/APF) recorded increasing in Shore hardness. This is interpreted by the good dispersion of the fiber in the matrix with the decrease of the voids and a higher fiber-matrix interfacial adhesion [52]. The lower values for alkalited composites (PVC/NPF) compared to untreated fibers are explained by the removal of hard constituents in palm fibers after treatments, hence the decrease in fiber hardness.

\subsubsection{Thermal stability}

The thermal stability of neat PVC and PVC/ palm date fiber composites was investigated with thermal analysis, and the results are shown on the TG thermograms of Figure 6.a and the DTG thermograms of Figure 6.b. The TG thermograms are identical for PVC matrix and the different composites. Several important thermal parameters are derived from these data, such as onset decomposition temperature, temperature and maximum speed, and residue rate. These properties are summarized in Table 2.

From the results obtained, it is noted that the onset decomposition temperature of PVC is slightly higher than those of PVC/UPF, PVC/APF, and PVC/NPF. Decrease of the degradation temperature with the addition of untreated fibers (PVC/UPF) explained by the poor adhesion between fibers and polymer chains which increase the friction between these chains with the rise in temperature causing the release of the hydrogen chloride gas [53]. For composites with acetylated fibers PVC/APF, there is an increase in the onset of degradation temperature over untreated fiber composites; this may be related to the increase of hydrogen bonds in acetylated fibers which requires significant break energies [35, 54].

Date palm fibers treated with sodium hydroxide caused the decrease of the onset decomposition temperature for composites; it is $228.1{ }^{\circ} \mathrm{C}$, for $\mathrm{PVC} / \mathrm{NPF}_{30}$ formulations compared to that of untreated fiber composites $\mathrm{PVC} / \mathrm{UPF}_{30}$ which is $229^{\circ} \mathrm{C}$. This result probably due to the polarity of the fiber which has decreased in the case of mercerization in an alkaline solution, elimination of part of the lignin (more or less hydrophobic element and therefore more or less polar is eliminated). El Mechtali et al. [55] proceeded with the alkaline treatment of the almond shell particles and found a decrease in the temperature of the beginning of decomposition which they attribute to the decrease of the lignin content.

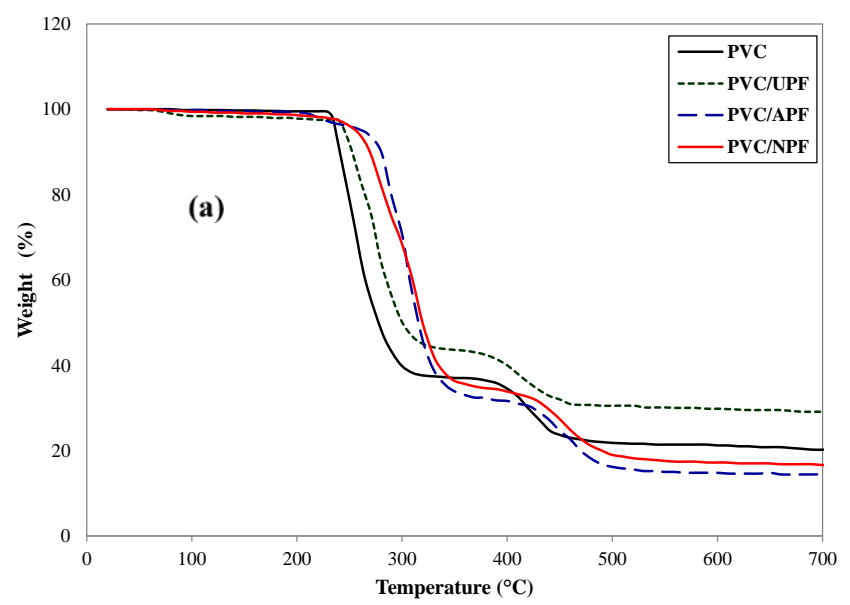

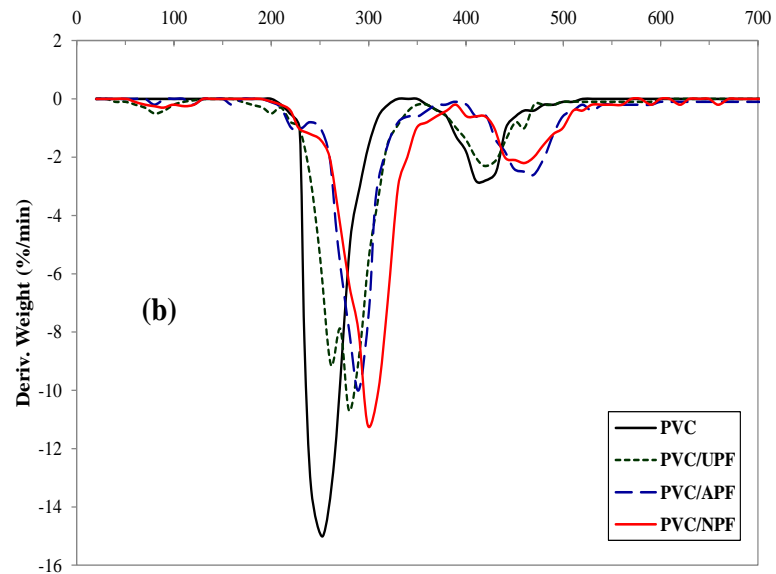

Figure 6. Thermograms of weight loss (a), and derivative weight loss (b) of neat PVC and composites with $30 \mathrm{wt} \%$ of treated and untreated fibers.

Composites samples exhibit a more stable thermal behavior than PVC after the onset decomposition temperature. This is due to a better intrinsic thermal stability of the cellulose fibers. Indeed, we can clearly see a decrease in the maximum decomposition rate of composites compared to that of PVC and we record a shift of temperature and maximum speed to the highest values. The results show that the introduction of the fiber into the PVC reduces the decomposition rate a sign of a better thermal behavior. The results are in agreement with the work of Ge et al. [56].

The DTG thermogram of untreated fiber composites, we notice the appearance of peaks around $80-120{ }^{\circ} \mathrm{C}$ which corresponds to the evaporation of the water physically adsorbed on the surface of the particles of the date palm fiber for untreated composites. This phenomenon can be attributed to the hydrophilic nature of untreated fibers that have the ability to absorb more water molecules. On the other hand, in the same temperature range, the polyvinyl chloride does not record any peak, which is the signature of the hydrophobic character of the PVC matrix.

Table 2. Thermal degradation and derivative weight loose of each thermal degradation stage with $30 \mathrm{wt} \%$ of fiber

\begin{tabular}{|c|c|c|c|c|c|}
\hline \multicolumn{2}{|c|}{$\begin{array}{c}\text { Sample } \\
\text { designation }\end{array}$} & $\begin{array}{c}\text { PV } \\
\text { C }\end{array}$ & $\begin{array}{c}\text { PVC/UP } \\
\text { F } \\
\end{array}$ & $\begin{array}{c}\text { PVC/AP } \\
\mathbf{F} \\
\end{array}$ & $\begin{array}{c}\text { PVC/NP } \\
\text { F } \\
\end{array}$ \\
\hline \multicolumn{2}{|c|}{$\begin{array}{c}\text { Onset } \\
\text { decomposition } \\
\text { temperature }\left({ }^{\circ} \mathrm{C}\right)\end{array}$} & 234 & 229.0 & 231.3 & 228.1 \\
\hline \multirow[b]{2}{*}{$\begin{array}{l}\text { First } \\
\text { Stage }\end{array}$} & $\begin{array}{l}\mathrm{T}_{\max } \\
\left({ }^{\circ} \mathrm{C}\right)\end{array}$ & 253 & 280.0 & 289.7 & 299.2 \\
\hline & $\begin{array}{c}\mathrm{V}_{\max } \\
(\% / \min \\
)\end{array}$ & 15.0 & 10.7 & 12.6 & 11.2 \\
\hline $\begin{array}{l}\text { Secon } \\
\quad \mathrm{d}\end{array}$ & $\begin{array}{l}\mathrm{T}_{\max } \\
\left({ }^{\circ} \mathrm{C}\right) \\
\mathrm{V}_{\max }\end{array}$ & 410 & 419.0 & 469.7 & 460.2 \\
\hline Stage & $\begin{array}{c}(\% / \mathrm{min} \\
)\end{array}$ & 2.8 & 2.3 & 2.6 & 2.2 \\
\hline \multicolumn{2}{|c|}{ Residual rate (\%) } & 20.0 & 29.0 & 14.2 & 16.6 \\
\hline
\end{tabular}

\subsubsection{Water absorption}

The evolution of the water absorption of polyvinyl chloride composites with 10 and $30 \%$ of untreated fibers (Figure 7), mark an increase in the rate of water uptake with the incorporation of fibers in the matrix. Indeed, this is due to 
hydrophilic nature of palm fibers, where, hydrogen bonds formed between water molecules and $-\mathrm{OH}$ groups present in cellulose and hemicellulose [57].

Acetylated composites (PVC/APF) show lower absorption compared to untreated composites. This indicates that the acetylation treatment improves the dispersion of the fibers, where by the acetyl groups make the surface of the fiber more hydrophobic. The reactive hydroxyl groups are the minor constituents of the fiber, i.e. lignin and hemicelluloses, and of amorphous cellulose [58].

Composites reinforced with alkali fibers (PVC/NPF) absorb more than untreated composites. This increase in absorption can be attributed to the removal of lignin which is hydrophobic, conversion of cellulose structure and improvement of interfacial adhesion [59]. Although there are others have found that this treatment decreases the water absorption that expressed by the strong adhesion in their composites.

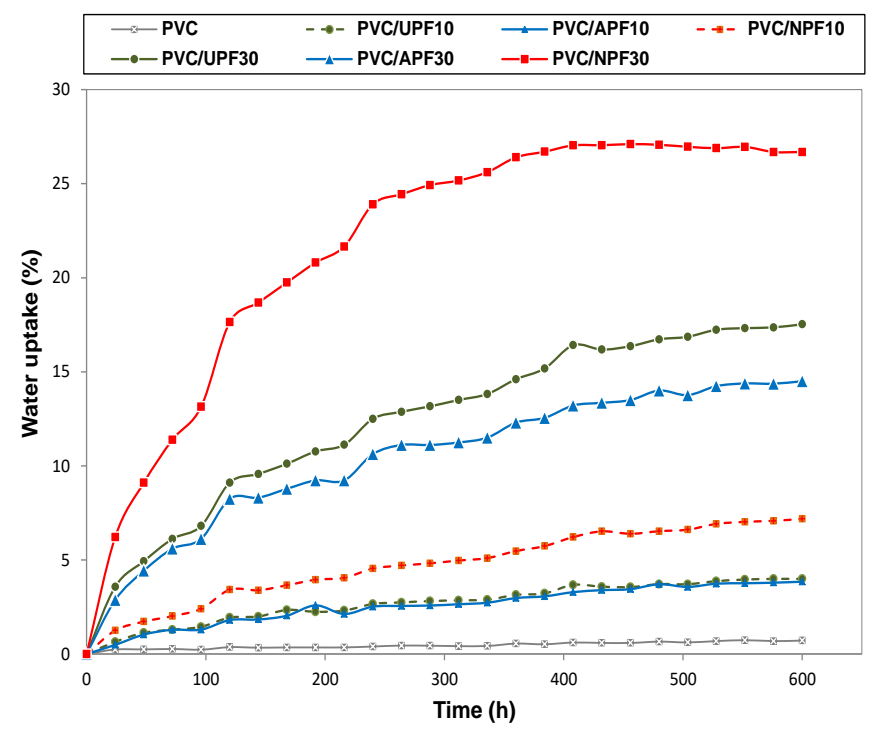

Figure 7. Water absorption of neat PVC and composites with treated and untreated fibers

\section{CONCLUSIONS}

In this paper, date palm fibers reinforced PVC composites with and without treatments were compounded and pressed into test samples with a loading rate of 10 and $30 \mathrm{wt} \%$. The mechanical, thermal properties and water uptake of composites were compared and analyzed against neat PVC. The results show a change in structural of the fibers after treatments by the reduction of hydroxyl group band intensity of cellulose. The alkaline treatment leads to the partial disappearance of hemicellulose and lignin. The use of acetylated fibers in PVC composites improves the mechanical properties of the composite due to the chemical bonding between the fibers surface and the polymeric matrix.

The evaluation of the thermal properties of the composites shows the decomposition temperature of composites increase from $229^{\circ} \mathrm{C}$ (untreated composites) to $231.3^{\circ} \mathrm{C}$ and $228.1^{\circ} \mathrm{C}$ (acetylated and alkali composites, respectively), with fibers loading of $30 \mathrm{wt} \%$. Water uptake test shows increase the absorption with the fiber content and the immersion time. The acetylated composites show the lowest rate of water absorption.

\section{REFERENCES}

[1] Khan RA, Zaman HU, Khan MA, Nigar F, Towhidul I, Rafiqul I, Suvasree S, Rahman MM, Mustafa AI, Gafur MA. (2010). Effect of the incorporation of PVC on the mechanical properties of the jute-reinforced LLDPE composite. Polymer-Plastics Technology and Engineering 49: 707-712. https://doi.org/10.1080/03602551003749544.

[2] Mishra S, Mohanty AK, Drzal LT, Misra M, Parija S, Nayak SK, Tripathy SS. (2003). Studies on mechanical performance of biofiber/glass reinforced polyester hybrid composites. Composites Science and Technology 63: 1377-1385. http://dx.doi.org/10.1016/S02663538(03)00084-8

[3] Rafiqul I, Towhidul I, Nigar F, Suvasree S, Arifuzzaman T, Sharmin N, Dey K, Mustafa AI, Khan RA, Khan MA, Zaman HU. (2011). Fabrication and mechanical characterization of jute fabrics: Reinforced polyvinyl chloride/polypropylene hybrid composites. International Journal of Polymeric Materials and Polymeric Biomaterials 60: 576-590. https://doi.org/10.1080/00914037.2010.531822

[4] Karuppuchamy S. (2015). Thermo-mechanical properties of coconut shell powder reinforced plastic composites. International Journal of ChemTechResearch 8: 852-857.

[5] Athijayamani A, Thiruchitrambalam M, Natarajan U, Pazhanivel B. (2010). Influence of alkali-treated fibers on the mechanical properties and machinability of roselle and sisal fiber hybrid polyester composite. Polymer Composites 31: 723-31. https://doi.org/10.1002/pc.20853

[6] MegiattoJr JD, Silva CG, Derval SR, Frollini E. (2008). Sisal chemically modified with lignins: Correlation between fibers and phenolic composites properties. Polymer Degradation and Stability 93: 1109-1121. https://doi.org/10.1016/j.polymdegradstab.2008.03.011

[7] Suppakarn N, Jarukumjorn K. (2009). Mechanical properties and flammability of sisal/PP composites: Effect of flame retardant type and content. Composites Part B: Engineering 40: 613-8. https://doi.org/10.1016/j.compositesb.2009.04.005

[8] Hung KC, Wu JH. (2010). Mechanical and interfacial properties of plastic composite panels made from esterified bamboo particles. Journal of Wood Science 56: 216-221. https://doi.org/10.1007/s10086-009-1090-9

[9] Murali KMR, Mohana KR. (2007). Extraction and tensile properties of natural fibers: Vakka, date and bamboo. Composite $\quad$ Structures 77: 288-295. https://doi.org/10.1016/j.compstruct.2005.07.023

[10] Abdrahman MF, Zainudin ES. (2011). Properties of kenaf filled unplasticized polyvinyl chloride composites. Compos Sci Technol 471-472: 507-512. https://doi.org/10.4028/www.scientific.net/KEM.471472.507

[11] Cerqueiraa EF, Baptistab CARP, Mulinari DR. (2011). Mechanical behavior of polypropylene reinforced sugarcane Bagasse fibers composites. Procedia Engineering 10: 2046-2051 https://doi.org/10.1016/j.proeng.2011.04.339

[12] Hamid MRY, AbGhani MH, Ahmad S. (2012). Effect of antioxidants and fire retardants as mineral fillers on the physical and mechanical properties of high loading 
hybrid biocomposites reinforced with rice husks and sawdust. Industrial Crops and Products 40: 96-102. https://doi.org/10.1016/j.indcrop.2012.02.019

[13] Kriker A, Debicki G, Bali A, Khenfer MM, Chabannet M. (2005). Mechanical properties of date palm fibres and concrete reinforced with date palm fibres in hot-dry climate. Cement \& Concrete Composites 27:554-564.

[14] Agoudjil B, Benchabane A, Boudenne A, Ibos L, Fois M. (2011). Renewable materials to reduce building heat loss: Characterization of date palm wood. Energy and Buildings 43: 491-497. https://doi.org/10.1016/j.enbuild.2010.10.014

[15] Wielage B, Lampke TH, Utschick H, Soergel F. (2003). Processing of natural-fibre reinforced polymers and the resulting dynamic mechanical properties. Journal of Materials Processing Technology 139: 140-146. https://doi.org/10.1016/S0924-0136(03)00195-X

[16] Essabir H, Nekhlaoui S, Malha M, Bensalah MO, Arrakhiz FZ, Qaiss A, Bouhfid R. (2013). Biocomposites based on polypropylene reinforced with Almond Shells particles: Mechanical and thermal properties. Materials and Design 51: 225-230. https://doi.org/10.1016/j.matdes.2013.04.031

[17] Azwa ZN, Yousif BF, Manalo AC, Karunasena W. (2013). A review on the degradability of polymeric composites based on natural fibres. Materials and Design 47: 424-442. https://doi.org/10.1016/j.matdes.2012.11.025

[18] Joseph PV, Rabello MS, Mattoso LHC, Kuruvilla J, Sabu T. (2002). Environmental effects on the degradation behaviour of sisal fibre reinforced polypropylene composites. Composites Science and Technology 62: 1357-1372. 3538(02)00080-5

[19] Ray D, Sarkar BK. (2001). Characterization of alkalitreated jute fibres for physical and mechanical properties. Journal of Applied Polymer Science 80: 1013-1020. https://doi.org/10.1002/app.1184

[20] Mishra SB, Mishra AK, Kaushik NK, Khan MA. (2007). Study of performance properties of lignin-based polyblends with polyvinyl chloride. Journal of Materials Processing Technology 183: 273-276. http://dx.doi.org/10.1016/j.jmatprotec.2006.10.016

[21] John MJ, Anandjiwala RD. (2008). Recent developments in chemical modification and characterization of natural fiber-reinforced composites. Polymer Composites 29: 187-207. https://doi.org/10.1002/pc.20461

[22] Bledzki AK, Mamun AA, Lucka-Gabor M, Gutowski VS. (2008). The effects of acetylation on properties of flax fibre and its polypropylene composites. eXPRESS Polymer Letters 2: 413-422. https://doi.org/10.3144/expresspolymlett.2008.50

[23] Bledzki AK, Gassan J. (1999). Composites reinforced with cellulose based fibres. Progress in Polymer Science 24: 221-274. https://doi.org/10.1016/S00796700(98)00018-5

[24] Seena J, Koshy P, Thomas S. (2005). The role of interfacial interactions on the mechanical properties of banana fibre reinforced phenol formaldehyde composites. Composite Interfaces 12: 581-600. https://doi.org/10.1163/1568554054915183

[25] Liu FP, Wolcott MP, Gardner DJ, Rials T. (1994). Characterization of the interface between cellulosic fibers and a thermoplastic matrix. Composite Interfaces
2: 419-432. https://doi.org/10.1163/156855494X00319

[26] Chen CH, Li HC, Teng CC, Yang CH. (2006). Fusion, electrical conductivity, thermal, and mechanical properties of rigid poly(vinyl chloride) (PVC)/carbon black (CB) composites. Journal of Applied Polymer Science 99: 2167-2173. https://doi.org/10.1002/app.22656

[27] Sun S, Li C, Zhang L, Du HL. (2006). Interfacial structure and mechanical properties of PVC composites reinforced by $\mathrm{CaCO}_{3}$ with different particle sizes and surface treatment. Polymer International 55: 158-164. https://doi.org/10.1002/pi.1932

[28] Wirawan R, Zainudin ES, Sapuan SM. (2009). Mechanical properties of natural fiber reinforced PVC composites; A review. SainsMalaysiana, 38 (4): 531-535.

[29] Chigondo F, Shoko P, Nyamunda CB, Guyo U, Moyo M. (2013). Maize stalk as reinforcement in natural rubber composites. International Journal of Scientific and Technology Research 2: 263-271.

[30] Rahmoune MA, Benhamou A, Fernane F, Toufaily J. (2015). Effect of treatment with soda and dimethoxydimethylsilane on water absorption and thermal stability of olive pomace flour and date stone. Journal of Materials and Environmental Science 6: 26552664.

[31] Gañán P, Cruz J, Garbizu S, Arbelaiz A, Mondragon I. (2004). Stem and bunch banana fibers from cultivation wastes: Effect of treatments on physico-chemical behavior. Journal of Applied Polymer Science 94: 14891495. https://doi.org/10.1002/app.21061

[32] Bodîrlău R, Teacă CA. (2009). Fourier transform infrared spectroscopy and thermal analysis of lignocellulose fillers treated with organic anhydrides. Romanian Journal of Physics 54: 93-104.

[33] Nedjma S, Djidjelli H, Boukerrou A, Benachour D, Chibani N. (2012). Deinked and acetylated fiber of newspapers. Journal of Applied Polymer Science 123: 17. https://doi.org/10.1002/app.38048

[34] Bessadok A, Marais S, Roudesli S, Lixon C, Métayer M. (2008). Influence of chemical modifications on watersorption and mechanical properties of Agave fibres. Composites Part A: Applied Science and Manufacturing 39: 29-45. https://doi.org/10.1016/j.compositesa.2007.09.007

[35] Beztout M, Boukerrou A, Djidjelli H, Barres C, Fenouillot F. (2015). Effects of acetylation process and cellulose content on the mechanical, thermal, morphological and rheological properties of poly (vinyl chloride)/cellulose composites. Cellulose Chemistry and Technology Cellulose 49: 517-528.

[36] Mokaloba N, Batane R. (2014). The effects of mercerization and acetylation treatments on the properties of sisal fiber and its interfacial adhesion characteristics on polypropylene. International Journal of Engineering, Science and Technology 6: 83-97. http://dx.doi.org/10.4314/ijest.v6i4.9

[37] Madhuban G, Bhaduri SK, Banerjee SK, Sao KP. (1985). Acetylation of jute and infrared spectra of acetylated jute. Indian journal of textile research, 10: 68-70.

[38] Ikhlef S, Nekkaa S, Guessoum M, Haddaoui N. (2012). Effects of alkaline treatment on the mechanical and rheological properties of low-density polyethylene/spartiumjunceum flour composites. ISRN Polymer Science Journal 7-13. 
http://dx.doi.org/10.5402/2012/965101

[39] Jähn A, Schröder MW, Füting M, Schenzel K, Diepenbrock W. (2002). Characterization of alkali treated flax fibres by means of FT Raman spectroscopy and environmental scanning electron microscopy. Spectrochimica Acta. Part A, Molecular and Biomolecular Spectroscopy 58: 2271-2279. https://doi.org/10.1016/S1386-1425(01)00697-7

[40] Sgriccia N, Hawley MC, Misra M. (2008). Characterization of natural fiber surfaces and natural fiber composites. Composites Part A: Applied Science and Manufacturing 39: 1632-1637. https://doi.org/10.1016/j.compositesa.2008.07.007

[41] Boukerrou A, Hamour N, Djidjelli H, Hammiche D. (2012). Effect of the different sizes of the alfa on the physical, morphological and mechanical properties of pvc/alfa composites. Macromolecular Symposia: Polymer Blends 321: 191-196. https://doi.org/10.1002/masy.201251134

[42] Zafeiropoulos NE, Williams DR, Baillie CA, Matthews FL. (2002). Engineering and characterisation of the interface in flax fibre/polypropylene composite materials. Part I. Development and investigation of surface treatments. Composites Part A: Applied Science and Manufacturing 33: 1083-1093. https://doi.org/10.1016/S1359-835X(02)00082-9

[43] Tserki V, Zafeiropoulos NE, Simon F, Panayiotou C. (2005). A study of the effect of acetylation and propionylation surface treatments on natural fibres. Composites: Part A 36: 1110-1118. https://doi.org/10.1016/j.compositesa.2005.01.004

[44] Kumar SMS, Duraibabu D, Subramanian K. (2014). Studies on mechanical, thermal and dynamic mechanical properties of untreated (raw) and treated coconut sheath fiber reinforced epoxy composites. Materials and Design 59:

63-69.

http://dx.doi.org/10.1016/j.matdes.2014.02.013

[45] Bledzki AK, Letman M, Viksne A, Rence L. (2005). A comparison of compounding processes and wood type for wood fibre-PP composites. Composites: Part A 36: 789-797.

https://doi.org/10.1016/j.compositesa.2004.10.029

[46] Th.Georgopoulos S, Tarantili PA, Avgerinos E, Andreopoulos AG, Koukios EG. (2005). Thermoplastic polymers reinforced with fibrous agricultural residues. Polymer Degradation and Stability 90: 303- 312. https://doi.org/10.1016/j.polymdegradstab.2005.02.020

[47] Yao F, Wu Q, Lei Y, Xu Y. (2008). Rice straw fiberreinforced high-density polyethylene composite: Effect of fiber type and loading. Industrial Crops and Products 28: 63-72. https://doi.org/10.1016/j.indcrop.2008.01.007

[48] Anbukarasi K, Kalaiselvam S. (2015). Study of effect of fibre volume and dimension on mechanical, thermal, and water absorption behaviour of luffa reinforced epoxy composites, Materials and Design 66: 321-330. http://dx.doi.org/10.1016/j.matdes.2014.10.078

[49] Kaci M, Djidjelli H, Boukerrou A, Zaidi L. (2007). Effect of wood filler treatment and EBAGMA compatibilizer on morphology and mechanical properties of low density polyethylene/olive husk flour composites. eXPRESS Polymer Letters 1: 467-473. http://dx.doi.org/10.3144/expresspolymlett.2007.65

[50] Nedjma S, Djidjelli H, Boukerrou A, Grohens Y, Chibani N, Benachour D, Pillin I. (2014). Effect of chemical treatment on newspaper fibers reinforced polymer poly(vinyl chloride) composites. Journal of Vinyl \& Additive Technology 22: 173-181. https://doi.org/10.1002/vnl.21425

[51] Nazrul MI, Rezaur MR, Mominul H, Huque MM. (2010) Physico-mechanical properties of chemically treated coir reinforced polypropylene composites. Composites Part A Applied Science and Manufacturing 41: 192-198. https://doi.org/10.1016/j.compositesa.2009.10.006

[52] Rezaur MR, Huque MM, Nazrul MI, Hasan M. (2009). Mechanical properties of polypropylene composites reinforced with chemically treated abaca. Composites Part A: Applied Science and Manufacturing 40: 511-517. https://doi.org/10.1016/j.compositesa.2009.01.013

[53] Qian S, Wang H, Zarei E, Sheng K. (2015). Effect of hydrothermal pretreatment on the properties of moso bamboo particles reinforced polyvinyl chloride composites. Composites Part B: Engineering 82: 23-29. https://doi.org/10.1016/j.compositesb.2015.08.007

[54] Abdul Khalil HPS, Tehrani MA, Davoudpour Y, Bhat AH, Jawaid M, Hassan A. (2012). Natural fiber reinforced poly(vinylchloride) composites: A review. Journal of Reinforced Plastics and Composites 32: 330356. https://doi.org/10.1177/0731684412458553

[55] El Mechtali FZ, Essabir H, Nekhlaoui S, Bensalah MO, Jawaid M, Bouhfid R, Qaiss AE. (2015). Mechanical and thermal properties of polypropylene reinforced with almond shells particles: Impact of chemical treatments. Journal of Bionic Engineering 12: 483-494. https://doi.org/10.1016/S1672-529(14)60139-6

[56] Ge XC, Li XH, Meng YZ. (2004). Tensile properties, morphology, and thermal behavior of PVC composites containing pine flour and bamboo flour. Journal of Applied Polymer Science 93: 1804-1811. https://doi.org/10.1002/app.20644

[57] Yasuji K, Sei S. (2013). Preparation of acetylated wood meal and polypropylene composites II: mechanical properties and dimensional stability of the composites. Journal of Wood Science 59: 216-220. https://doi.org/10.1007/s10086-012-1316-0

[58] Supri AG, Lim BY. (2009). Effect of treated and untreated filler loading on the mechanical, morphological, and water absorption properties of water hyacinth fibers-low density polyethylene composites. Journal of Physical Science 20: 85- 96.

[59] Wirawan R., Sapuan SM, Robiah Y, Abdan K. (2011). Properties of sugarcane bagasse/poly (vinyl chloride) composites after various treatments. Journal of Composite Materials 45: 1667-1674. https://doi.org/10.1177/0021998310385030

\section{NOMENCLATURE}

$\begin{array}{ll}\text { PVC } & \text { Polyvinyl chloride } \\ \text { DPF } & \text { Date palm fibers }\end{array}$

PVC/UPF Polyvinyl chloride composite with untreated

PVC/APF Polyvinyl chloride composite with acetylated fibers

PVC/NPF Polyvinyl chloride composite with acetylated fibers 